\title{
COVID-19 impact on research and publication ethics
}

\author{
Fatemeh Heidary ${ }^{1}$ and Reza Gharebaghi ${ }^{1}$ \\ ${ }^{1}$ International Virtual Ophthalmic Research Center, Austin, Texas, United States
}

\author{
KEYWORDS \\ COVID-19, research, publication ethics, retraction, biomedicine, ethics
}

\section{INTRODUCTION}

The COVID-19 pandemic has caused immense hardship and human tragedy over the past year, affecting all aspects of life. The human community that boasted of modern diagnostic and treatment technologies continues to remain in a state of shock.

The pandemic has once again proved that science still has a long way to go. Given the challenges that COVID-19 has brought with it, it is imperative for different disciplines of the research community to study this contagion [1]. The impact of this disease on human life cannot be remedied for many years to come. Furthermore, COVID-19 has affected the path of medicine and research as well. This editorial offers a brief outline of the challenges COVID-19 has created in publication ethics.

\section{Acceleration or Precision}

The pandemic has distorted the scientific pathway since the beginning of 2020. The lockdown imposed following its outbreak made an increase in the number of papers submitted by researchers. Several journals have shown haste both in peer review and acceptance of COVID-19-related papers [2]. Studies revealed that in the initial months of the pandemic, submissions to journals showed an irregular and exponential growth. In the first wave of the pandemic, compared to other time periods, there were fewer research articles by female authors compared to their male colleagues, which could be attributed to the additional responsibilities that women shoulder at home [3].

"The pandemic has given incredible opportunities for researchers but it has also been a shock to the academic system, with an explosion of publications and citations for COVID-19 papers. This is distorting the rewards of science. We need to make sure these things are taken into account when promoting and hiring in the years ahead," says Professor Flaminio Squazzoni [2], a social scientist at the University of Milan, Italy.

A sense of social responsibility amid the lockdown prompted researchers, who were mostly confined to their houses, to suspend their respective fields of interest, and switch to COVID-19 studies. The large number of submissions on the one hand and journals' inclination to publish more papers on COVID-19 on the other, made the ethical process of peer reviewing challenging, with many papers being retracted in a short timeframe.

Furthermore, studies other than those assessing life-saving therapies ceased, and new strategies were developed to protect research subjects, physician-scientist careers, and the research community [4]. Meanwhile, funding agencies focused on the ongoing health crisis by investing in various aspects of the disease.

\section{The Retraction Tsunami}

Committee on Publication Ethics (COPE) guideline defined that "Retraction is a mechanism for correcting the literature and alerting readers to publications that contain such seriously flawed or erroneous data that

Correspondence: Reza Gharabaghi MD MPH FAAO, International Virtual Ophthalmic Research Center, Austin, Texas, United States. Email: drgharebaghi@ yahoo.com. ORCID iD: https://orcid.org/0000-0002-4906-8597

How to cite this article: Heidary F, Gharebaghi R, COVID-19 impact on research and publication ethics. Med Hypothesis Discov Innov Ophthalmol. 2021 Spring; 10(1): 1-4. https://doi.org/10.51329/mehdiophthal1414

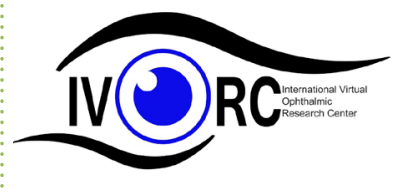

Copyright (C) Author(s). This is an open-access article distributed under the terms of the Creative Commons Attribution-NonCommercial 4.0 International License (http://creativecommons.org/licenses/by-nc/4.0/) which permits copy and redistribute the material just in noncommercial usages, provided the original work is properly cited. (c) (i) \&) 
their findings and conclusions cannot be relied upon. Unreliable data may result from honest error or from research misconduct" [5].

The rate of COVID-19 related publications is estimated to be 137 papers a day since February 2020 and is exceptionally high. Based on the Retraction Watch Database, a tool for monitoring retracted papers, on May 19, 2021109 research articles concerning COVID-19 were retracted. Furthermore, 12 papers were retracted owing to journal error, 4 were retracted and reinstated, and 6 expressions of concern were published $[6,7]$.

Although studies show that retractions take around three years on average, for COVID-19 literature, this timeframe has been reduced to only a few months. However, considering the short timeframe, a fair comparison may not be possible. One possible reason for this exceptionally high rate is that COVID-19related studies are under strict scrutiny [8].

Consequently, journals revised their peer review processes in haste. For instance, a study on the effects of hydroxychloroquine on COVID-19 was published in the Lancet, which was later retracted and led to the designing of a new independent peer review system concerning papers containing large datasets or real-world data. This even led to the use of experts in data science, besides statistical peer reviewers, with particular focus on data sharing statement [9]. The logic behind the retraction justification of those papers could be easily found in related journals' websites as well as in the Retraction Watch Database, which also contains data of papers with expressions of concern and corrections. However, research communities who are concerned about science integrity believe that the standards of peer reviewing and publication are in a dire need of restructuring in order to reduce the incidence of retraction owing to misconduct. Nonetheless, these revisions should not by any means lead to the emergence of a new bureaucracy.

One of the suggestions includes arranging for three independent peer reviewers for papers that introduce new medical treatment and/or are multi-centered studies with a large dataset; and we call this three-member jury, "important authorities" in peer reviewing to verify the qualification of the research article. One is a field expert peer reviewer who reviews the subject in his/her specialty field. A reviewer should peer review the subject in terms of compatibility with the principles of ethics, and an expert checks the details of the datasets and statistical integrity of the research article. Perhaps with the three-member teams that we call FES (Field expert, Ethics expert, and Statistical peer reviewer), the volume of retracted papers could be reduced.

Undoubtedly, one must consider the major challenges faced by journals as well as the shortage of peer reviewers. This means that as the number of papers increases, journals should proportionally hire more peer reviewers. Of note, impartial peer reviewers who independently and without any conflict of interest peer review the subjects for a fee could be considered practical. However, to materialize this suggestion, further elaboration and more papers are needed on this subject by different experts in this area.

\section{Is preprint good or bad? It's actually both!}

A preprint is a full-draft research paper that is publicized prior to the formal peer review process. The pandemic has increased the volume of preprint papers. The first preprint study on COVID-19 was published on January 19, 2020, and thousands of articles were published subsequently. Although studies show that the average normal period for the peer reviewing process is 125 days, many of preprints published papers in less than a week [10]. What they do is an initial screening with a few editorial formalities, the details of which are available on preprint websites. Although preprints as open publishing platforms provide early access to research outputs, the fact that the papers are not peer reviewed in formal processes has created deep controversies and concerns. Table 1 briefly lists the advantages and disadvantages of preprints [11-15].

\section{CONCLUSIONS and OUTLOOK}

Many studies on subjects, other than COVID-19, have been stopped taking into consideration public and researchers' health. The future of medical science and chronic diseases has been intensely affected. Despite the vast propaganda, statistics show that COVID-19 was the third most common cause of death in the US after heart disease and cancer [16]. Accordingly, addressing COVID-19 should not compromise the flow of research on other risk factors of human health. Meanwhile, the future of COVID-19 remains unclear.

Despite advancements in vaccines, one cannot give a definite view of the future perspective of preventing and treating this disease and people's restoration of their normal lives. It seems that simple health recommendations, such as social distancing and using masks, continue to be effective in controlling COVID-19. Despite the inter-connectiveness of the human community, no consistent and universal agreement is seen globally on conducting a universal collaboration to combat this crisis.

Although most reliable publishers have given free access to COVID-19-related papers, based on a study, 
three quarters of the papers, are charged for accessibility. In this regard, open access to all health-related scientific papers is necessary [10]. One must be alert, trust the scientists, and wait for additional research.

Nonetheless, a major risk is threatening the world alongside COVID-19, that is, inefficient policymakers and some greedy commercial companies. The policymakers help in the durability of this disease and, subsequently, its enhanced damages by bringing political interests into science. Conversely, commercial companies are looking to gain more profits, which do not necessarily appear in line with the path of scientific growth, even if they appear in alignment. It is the duty of civil organizations and authorities to publicize corruption and prevent people's lives from becoming a means to satisfy greed.

There are still many conflicts in vision science; for example, in most low- and middle-income countries, primary eye care services are deficient and are negligently integrated into primary health care [17]. Although many people around the world suffer from avoidable causes of blindness, some of the investments are on facilities and medications that do not aim to solve major problems in the world population to treat and prevent avoidable causes of blindness.

Meanwhile, many useful modalities of treatment for ocular health are off-label, including intravitreal antibiotics for endophthalmitis and bevacizumab for neovascular age-related macular degeneration [18]. It seems that there is no one to undertake the necessary budget for the registry and lead associated studies.

These conflicts indicate the involvement of power and wealth in science that have in turn affected vision science. Effective policy making can save humanity and address an upcoming crisis that threatens communities.

\section{ETHICAL DECLERATIONS}

Ethical approval: Not needed.

Conflict of interests: Dr. Fatemeh Heidary assigned as Editor in Chief Medical Hypothesis, Discovery \& Innovation in Ophthalmology.

\section{FUNDING}

None.

\section{ACKNOWLED GEMENT}

None.

Table 1. Summary of advantages and disadvantages of preprint publication [11-15]

\begin{tabular}{|l|l|}
\hline Advantages & Disadvantages \\
\hline Prompt dissemination of outcomes & Lack of peer-review \\
\hline Contributes to free flow of information & Absence of quality (controversy) \\
\hline Increased chances of early feedback and comments & Concerns about premature data \\
\hline Increased citations & Media coverage without robust evaluation \\
\hline Chances of academic collaborations & $\begin{array}{l}\text { Risk of double citation (By publishing a peer- reviewed article, the } \\
\text { preprint may also be cited) }\end{array}$ \\
\hline Make authors enthusiastic & Lack of ethical and statistical guidelines \\
\hline May reduce predatory publishing & Lack of respect for COPE and ICMJE \\
\hline Increases transparency & Breach of intellectual property regulations in some countries \\
\hline May publish negative outcomes and controversies & Possible harm to health in certain cases \\
\hline May receive DOI, link to ORCID, and plagiarism check & Information overload \\
\hline Chance to receive grants and awards & $\begin{array}{l}\text { Breach of Ingelfinger rule (a strategy conducted to discourage dis- } \\
\text { semination of research reports before they are published in the } \\
\text { journal) }\end{array}$ \\
\hline Promotion of young researchers & Rush to post low-quality research \\
\hline Early credit & \\
\hline Good place for hypothesis & \\
\hline Early detection of science misconduct & \\
\hline Ab & \\
\hline
\end{tabular}

Abbreviations: DOI, digital object identifier; ORCHID, Open Researcher and Contributor ID or identifier; COPE, Committee on Publication Ethics; ICMJE, International Committee of Medical Journal Editors. 


\section{REFERENCES}

1. Gharebaghi R, Heidary F. Social and Academic Responsibility Given COVID-19 Pandemic. Iran J Public Health. 2020;49:134-5. doi: $10.18502 /$ ijph.v49iS 1.3687

2. Else H. How a torrent of COVID science changed research publishing - in seven charts. Nature. 2020;588(7839):553. doi: 10.1038/ d41586-020-03564-y pmid: 33328621

3. Squazzoni F, Bravo G, Grimaldo F, Garcia-Costa D, Farjam M, Mehmani B. (2020). 'Only second-class tickets for women in the COVID-19 race. A study on manuscript submissions and reviews in 2329 Elsevier journals' [Online, October 16, 2020]. Available at: SSRN: https://ssrn.com/abstract=3712813 or doi: 10.2139/ssrn.3712813 (Accessed: May 31, 2021).

4. Weiner DL, Balasubramaniam V, Shah SI, Javier JR, Pediatric Policy C. COVID-19 impact on research, lessons learned from COVID-19 research, implications for pediatric research. Pediatr Res. 2020;88(2):148-50. doi: 10.1038/s41390-020-1006-3 pmid: 32544922

5. COPE. (2009) 'Retractions: Guidance from the Committee on Publication Ethics (COPE)' [Online] Available at: https://publicationethics.org/files/u661/Retractions_COPE_gline_final_3_Sept_09_2_.pdf (Accessed: May 31, 2021) [Internet].

6. Yeo-Teh NSL, Tang BL. An alarming retraction rate for scientific publications on Coronavirus Disease 2019 (COVID-19). Account Res. 2021;28(1):47-53. doi: 10.1080/08989621.2020.1782203 pmid: 32573274

7. Retraction, Watch. (2021) 'Retracted coronavirus (COVID-19) papers' [Online] Available at: https://retractionwatch.com/retracted-coronavirus-covid-19-papers/ (Accessed: May 19, 2021) [Internet].

8. Abritis A, Marcus A, Oransky I. An "alarming" and "exceptionally high" rate of COVID-19 retractions? Account Res. 2021;28(1):58-9. doi: $10.1080 / 08989621.2020 .1793675$ pmid: 32634321

9. The Editors Of The Lancet G. Learning from a retraction. Lancet. 2020;396(10257):1056. doi: 10.1016/S0140-6736(20)31958-9 pmid: 32950071

10. Kiley R. (2020) 'Three lessons COVID-19 has taught us about open access publishing' [Online] Available at: https://blogs.lse.ac.uk/ impactofsocialsciences/2020/10/06/39677/ (Accessed: May 19, 2021) [Internet].

11. Eysenbach G. The impact of preprint servers and electronic publishing on biomedical research. Curr Opin Immunol. 2000;12(5):499503. doi: 10.1016/s0952-7915(00)00127-8 pmid: 11007350

12. Vlasschaert C, Giles C, Hiremath S, Lanktree MB. Preprint Servers in Kidney Disease Research: A Rapid Review. Clin J Am Soc Nephrol. 2021;16(3):479-86. doi: 10.2215/CJN.03800320 pmid: 32680914

13. Fry NK, Marshall H, Mellins-Cohen T. In praise of preprints. Microbiology (Reading).2019;165(5):489-91. doi: 10.1099/mic.0.000785 pmid: 30938669

14. Bourne PE, Polka JK, Vale RD, Kiley R. Ten simple rules to consider regarding preprint submission. PLoS Comput Biol. 2017;13(5):e1005473. doi: 10.1371/journal.pcbi.1005473 pmid: 28472041

15. Ferreira CM, Serpa S. The importance of preprint in scientific publication. Journal of Social Sciences Research. 2018;4(12):642-7.

16. Ahmad FB, Anderson RN. The Leading Causes of Death in the US for 2020. JAMA. 2021;325(18):1829-30. doi: 10.1001/ jama.2021.5469 pmid: 33787821

17. Cicinelli MV, Marmamula S, Khanna RC. Comprehensive eye care - Issues, challenges, and way forward. Indian J Ophthalmol. 2020;68(2):316-23. doi: 10.4103/ijo.IJO_17_19 pmid: 31957719

18. Gopal AD, Wallach JD, Shah SA, Regillo C, Ross JS. On-Label and Off-Label Clinical Studies of FDA-Approved Ophthalmic Therapeutics. Ophthalmology. 2021;128(2):332-4. doi: 10.1016/j.ophtha.2020.07.028 pmid: 32682839 